\title{
SISTEM INFORMASI PERSEDIAAN BARANG PADA BENGKEL SABAR JAYA MOTOR BERBASIS JAVA NETBEANS
}

\author{
Toetik Ayuwulandari ${ }^{1}$, Alusyanti Primawati ${ }^{2}$, Maria Cleopatra ${ }^{3}$ \\ ${ }^{1,2,3}$ Universitas indraprasta PGRI \\ Jalan Raya Tengah Gedong ,Pasar Rebo, Jakarta Timur, Daerah Khusus Ibukota Jakarta 13760 \\ 1wulandari12944@gmail.com, ${ }^{2}$ alus.unindra23@gmail.com, ${ }^{3}$ mariacleopatra1313@gmail.com
}

\begin{abstract}
ABSTRAK
Bengkel Sabar Jaya Motor adalah toko yang berfokus pada penjualan barang kebutuhan mobil, dan melayani jasa perbaikan mobil. Selama penelitian menemukan bahwa pada pembuatan laporan masih kurang diperhatikan oleh pemilik bengkel, hal ini dikarenakan belum pernah menggunakan sistem informasi persediaan barang pada proses persediaan di Bengkel Sabar Jaya Motor. Tujuan penelitian ini membuat sistem aplikasi persediaan barang yang diharapkan dapat mempermudah semua kegiatan yang berhubungan dengan pengolahan data barang, data barang masuk, data barang keluar, yang terdapat di Bengkel Sabar Jaya Motor agar menjadi efektif dan efisien. Dalam penelitian ini menggunakan metode grounded serta menggunakan bahasa pemrograman Java Netbeans. Hasil penelitian dari penelitian ini, yaitu memberikan fasilitas kecepatan dan ketepatan dalam melakukan proses pendataan persediaan membuat pemilik atau karyawan lebih mudah dalam pekerjaanya karena lebih efektif dan efisien.
\end{abstract}

Kata Kunci : Sistem, Persediaan Barang, Java Netbeans

\begin{abstract}
Bengkel Sabar Jaya Motor is a shop that focuses on selling car goods, besides that this workshop also provides car repair services. During the research, it was found that in making reports there was still less attention by the workshop owner, this was because they had never used an inventory information system in the inventory process at the Sabar Jaya Motor Workshop. The purpose of this study is to create an inventory application system that is expected to facilitate all activities related to processing goods data, incoming goods data, outgoing goods data, employee data and supplier data contained in the Sabar Jaya Motor Workshop to be effective and efficient. In this study using the grounded method and using the Java Netbeans programming language. The results of this study, namely providing facilities for speed and accuracy in carrying out the inventory data collection process, make it easier for owners or employees to work because they are more effective and efficient.
\end{abstract}

Key Word: System, Inventory, Java Netbeans

\section{PENDAHULUAN}

Sistem informasi merupakan hal yang penting dalam suatu organisasi atau perusahaan, dengan adanya suatu sistem informasi kualitas informasi yang disajikan organisasi maupun perusahaan dapat terjamin dan organisasi maupun perusahaan dapat mengambil keputusan berdasarkan informasi tersebut (Handayani et al., 2020). Sekarang berkat adanya teknologi informasi suatu informasi dapat diperoleh dengan lebih cepat dan mudah. Pemanfaatan teknologi informasi yang diharapkan adalah aplikasi inventori.

Sistem merupakan macam-macam komponen yang bekerja satu sama lain dalam satu unit tunggal untuk menjalankan suatu proses pencapaian tujuan utama, jaringan prosedur yang dibuat menurut pola yang terpadu untuk melaksanakan kegiatan-kegiatan pokok perusahaan, biasanya hal melibatkan beberapa orang dalam satu departemen atau lebih yang dibuat untuk menjamin suatu penanganan yang terjadi lebih dari sekali (Susanto, 2013).

Informasi merupakan suatu data yang telah diolah, diklarifikasikan serta di interprestasikan untuk proses pengambilan keputusan(Irviani, 2019). Selain sistem informasi merupakan sistem didalam suatu organisasi yang mempertemukan sebuah kebutuhan pengolahan transaksi harian, mendukung operasi dan kegiatan strategi dari suatu organisasi dan menyediakan informasi tertentu dengan laporan -laporan yang diperlukan (Syafitri \& Misgianti, 2017).

Pada umumnya persediaan merupakan salah satu jenis aktiva lancar yang memiliki jumlah cukup besar dalam suatu perusahaan 
(Alleonardo, 2014). Sebagai contoh dalam sebuah perusahaan disimpan untuk digunakan proses selanjutnya misalnya produksi atau perakitan yang hasil akhirnya nanti dapat dijual kembali agar dapat dimanfaatkan oleh orang lain . Dengan itu persediaan juga dapat diartikan sebagai proses penyimpanan barang yang akan digunakan untuk memenuhi keperluan tertentu (Huda et al., 2021).

Bengkel Sabar Jaya Motor adalah sebuah perusahaan yang bergerak di bidang penjualan barang dan memperbaiki mobil yang dibutuhkan pelanggan. Saat ini persaingan bisnis bengkel bukan hanya dipengaruhi oleh faktor harga, Melainkan juga mengarah pada persaingan dalam memberi pelayanan yang terbaik pada setiap pelanggan.

Di Bengkel Sabar Jaya Motor terdapat sistem pengolahan data. Pengolahan data sangat diperlukan dalam suatu manager untuk melihat laporan data barang yang masuk dari supplier, data barang yang keluar dan data stok barang, karena dengan pengolahan data ini dapat dilihat aliran data barang yang masuk dari supplier, data barang keluar, ataupun data stok barang yang ada di bengkel. Bengkel Sabar Jaya Motor masih menggunakan cara pengolahan data yang manual.

Tujuan dengan adanya suatu penelitian ini yaitu membuat suatu aplikasi yang sudah terkomputerisasi dan terhubung dengan database, yang membuat pemilik toko serta petugas pada Bengkel Sabar Jaya Motor dapat berjalan baik dalam proses pendataannya.

Manfaat yang diharapkan pada penelitian ini dapat menangani suatu permasalahan yang ada di toko, dalam membuat suatu pendataan dan membuat laporan kepada owner tersebut tidak mengalami kesalahan serta menbuatnya menjadi efisien dan efektif.

\section{METODE PENELITIAN}

Waktu penelitian yang dilakukan selama 5 bulan dimulai dari bulan april sampai agustus 2020. Dalam mengumpulkan data dan informasi yang diperlukan, penulis berusaha melakukan beberapa penelitian secara langsung ke Bengkel Sabar Jaya Motor yang beralamat di Jl. Raya Cileungsi - Jonggol Km.1 Prapatan Cileungsi.
Metode Penelitian yang digunakan adalah strategi grounded research, pada mulanya Grounded Exploration diciptakan pada tahun 1960-an oleh ahli sosiologi Barney Glaser dan Anselm Strauss yang hasilnya adalah Revelation of Grounded Hypothesis yang didistribusikan pada tahun 1967 (Wardhono, 2011). Menurut (Ayu \& Budiasih, 2013) Grounded Hypothesis adalah salah satu lingkup dari pemeriksaan penelitian subjektif adalah penelitian diarahkan oleh strategi pertemuan top to bottom dan pengalaman dari subjek penelitian.

Untuk menyempurnakan hasil dari penelitian ini, peneliti mencoba menuliskan langkahlangkah yang dilakukan dalam Perancangan Aplikasi persediaan barang pada Bengkel Sabar Jaya Motor. Dalam membuat langkahlangkah pengembangan sistem, digunakan metode terstruktur dengan Paradigma Siklus Hidup Klasik.

Berikut penjelasan aktivitas dalam langkahlangkah pengembangan sistem persediaan barang pada Bengkel Sabar Jaya Motor yaitu:

1. Analisis Kebutuhan Sistem

Ditahap menganalisa kebutuhan sistem perakitan kebutuhan dilakukan dengan memusatkan perhatian pada pemrograman, termasuk data, fungsi masing-masing dalam sistem, strategi kerja antarmuka . Tujuan dari analisis kebutuhan sistem yaitu mengurangi kesulitan yang terjadi pada proses pengolahan data dan proses pelaporan data di toko, serta meningkatkan layanan yang lebih baik bagi karyawan.

2. Studi Kepustakaan/ Studi Literatur

Dalam tahapan ini berfokus kepada pengumpulan data-data yang dibutuhkan dalam pengembangan sistem dengan membaca buku ilmiah, berkonsentrasi pada pokok permasalahan yang diidentifikasi dalam penulisan tugas akhir ini.

3. Pengumpulan Data dan Perancangan Sistem

Pada tahap ini setelah semua data yang dibutuhkan sudah didapat maka dilakukan perancangan struktur informasi, desain pemrograman, dan kualitas antarmuka yang pasti diselesaikan pada tahap ini. Juga tampilan layar yang direncanakan 
seperti form masukan dan form keluaran yang akan dirancang.

4. Pengkodean Sistem

Pada tahapan ini dilakukan pengkodean dari semua data yang telah di dapat ke dalam sebuah bahasa pemrograman dan di implementasikan ke dalam sebuah aplikasi dokumentasi pengajuan Asuransi agar lebih mudah digunakan.

5. Pengujian Sistem

Sebelum sistem aplikasi dokumentasi dapat digunakan dengan baik, maka harus melakukan pengujian terlebih dahulu. Serangkaian tes ini dijalankan bersama dengan informasi nyata dari kerangka kerja saat ini atau kerangka kerja yang sedang berjalan.

Tahapan-tahapan pada model waterfall dapat dilihat pada gambar 1 .

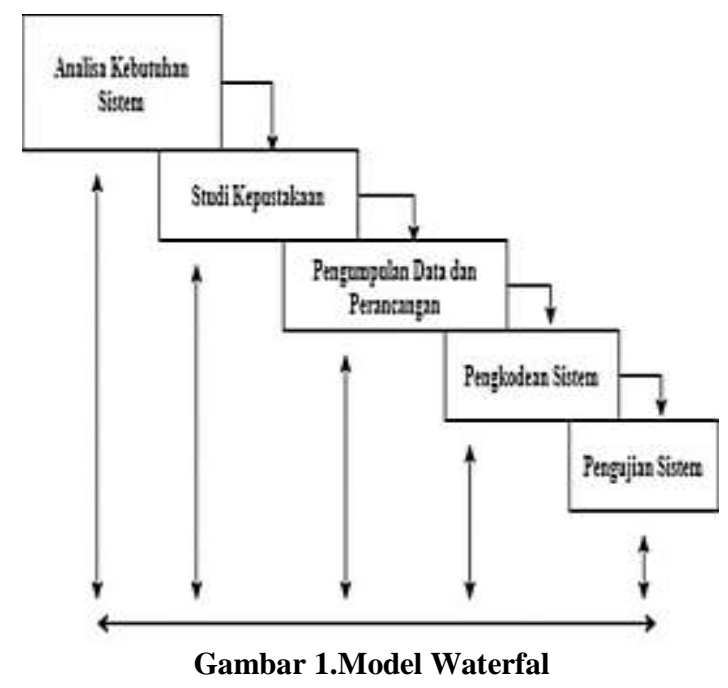

HASIL DAN PEMBAHASAN

Aplikasi sistem informasi persediaan barang pada Bengkel Sabar Jaya Motor yang terkomputerisasi dapat dihasilkan informasi yang lebih cepat, tepat dan akurat :

1. Persediaan barang yang sudah terkomputerisasi dapat membantu kinerja karyawan dalam pendataan barang.

2. Rancangan database sistem untuk penyimpanan data lebih efisien dan akurat.

3. Pembuatan sistem informasi yang dapat dipahami oleh semua pihak bengkel Sabar Jaya Motor.

\section{Diagram Konteks}

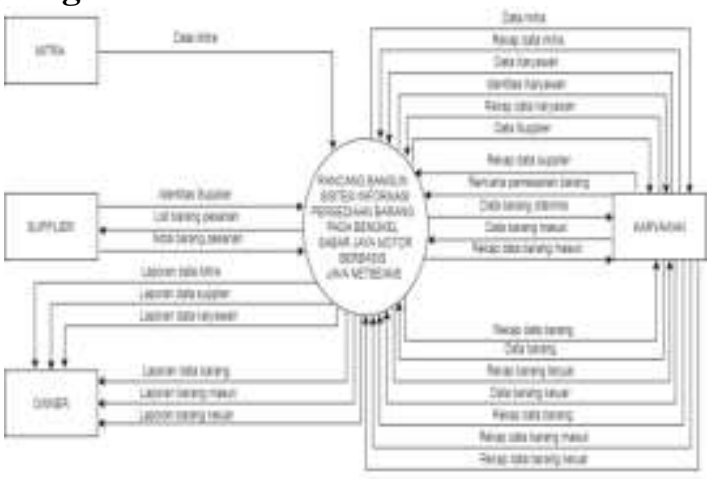

Gambar 2.Diagram konteks yang diusulkan

Diagram konteks merupakan diagram sederhana yang menggambarkan hubungan antara entitas luar, masukan dan keluaran dari sistem, diagram konteks dipresentasikan dengan lingkaran tunggal yang mewakili keseluruhan sistem (Fathia Risky \& Evayani, 2016).

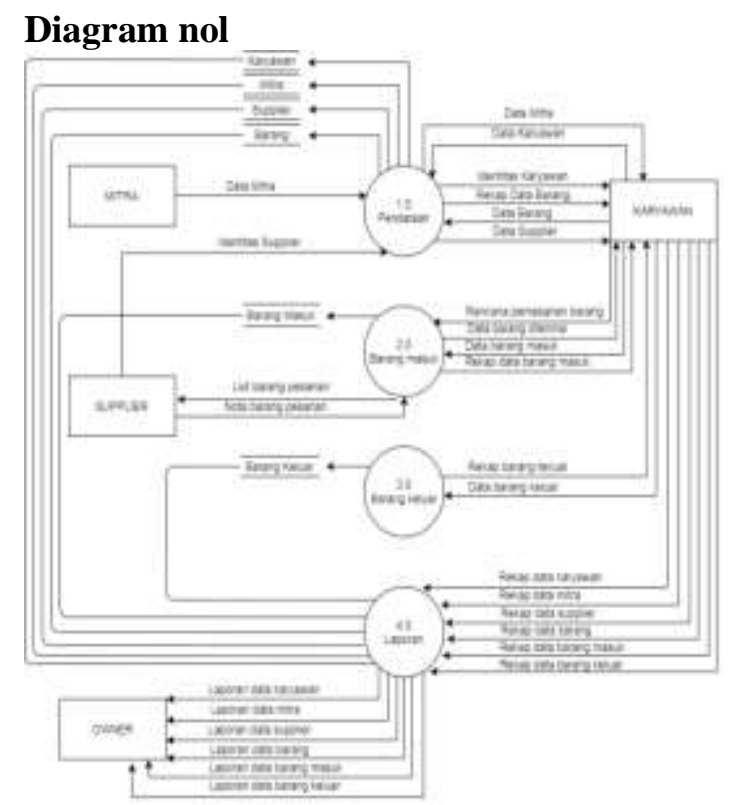

Gambar 3. Diagram nol yang diusulan

\section{Diagram Rinci yang Diusulan}

1. Diagram rinci proses 1.0

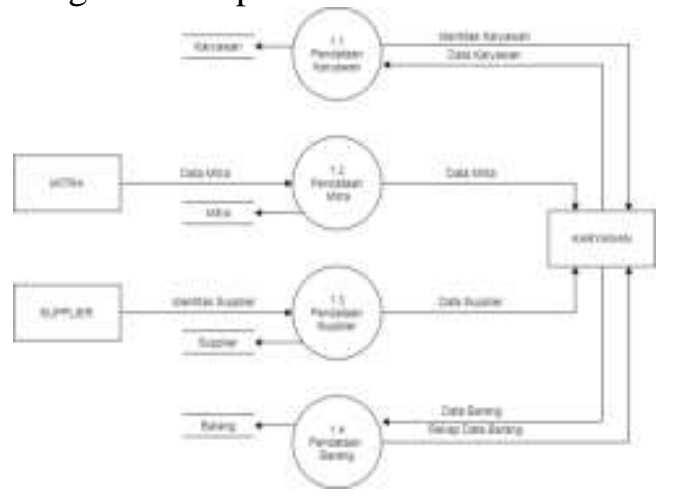

Gambar 4. Diagram rinci 1.0 yang diusulan 
2. Diagram rinci proses 2.0

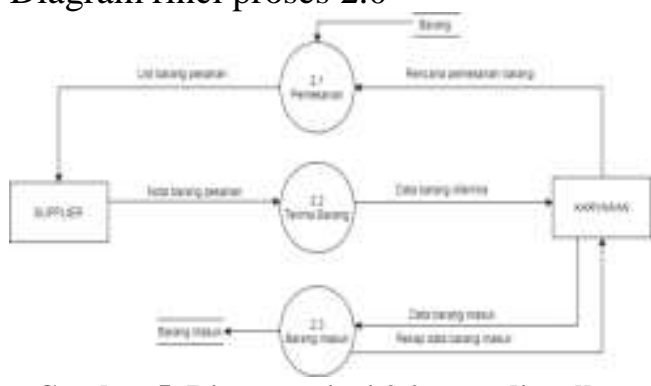

Gambar 5. Diagram rinci 2.0 yang diusulkan

3. Diagram rinci proses 3.0

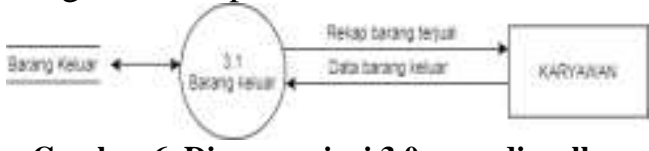

Gambar 6. Diagram rinci 3.0 yang diusulkan

4. Diagram rinci proses 4.0

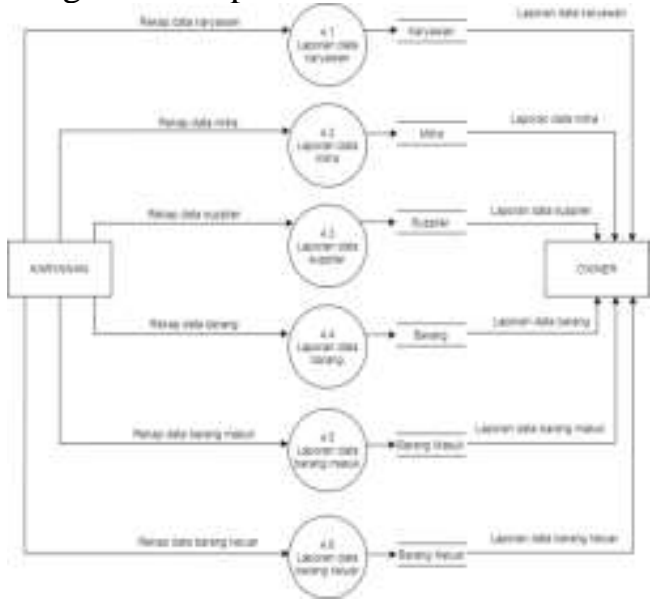

Gambar 7. Diagram rinci 4.0 yang diusulkan

\section{ERD (Entity Relationship Diagram)}

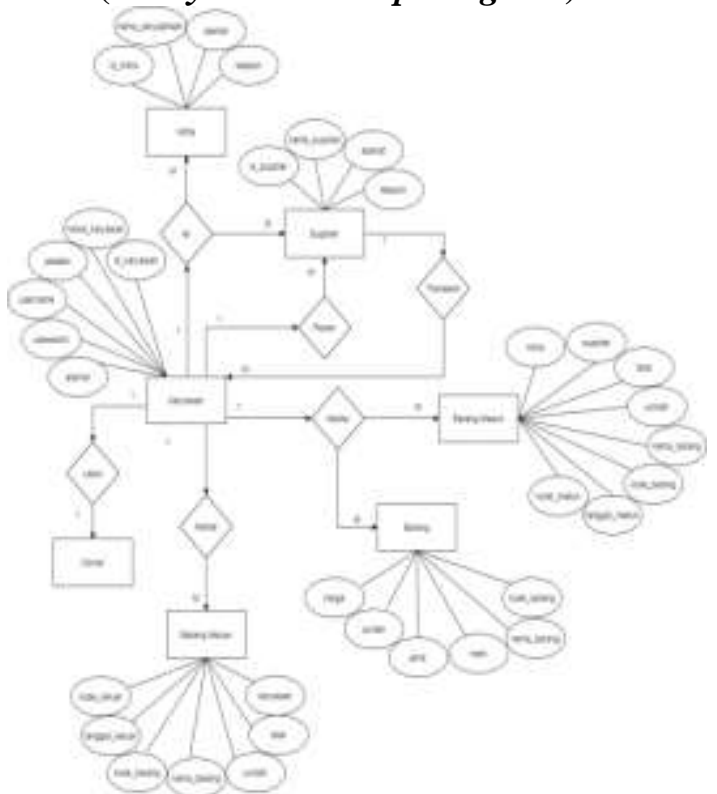

Gambar 8. ERD (Entity Relationship Diagram)
ERD merupakan sebuah metodologi Top-base dalam rencana kumpulan data yang dimulai dengan mengenali informasi utama yang disebut entitas, dengan membedakan informasi utama dalam perancangan basis data (Adrifa et al., 2018).

Berikut ini merupakan tampilan layar dan tampilan laporan dari hasil pengujian sistem informasi persediaan barang pada Bengkel Sabar Jaya Motor yang menggunakan bahasa pemograman Java.

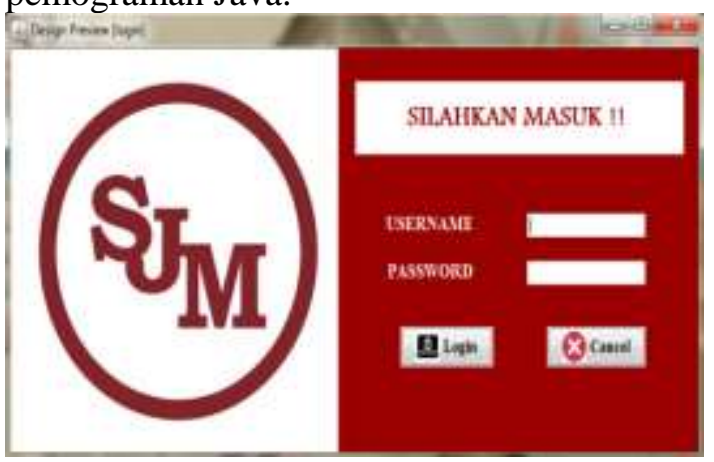

Gambar 9. Tampilan layar login

Tampilan login digunakan sebelum pengguna memulai program. Pengguna harus masukkan username dan password yang sesuai. Pada tampilan login terdapat tombol login yang berfungsi untuk masuk pada menu utama programe dan password yang dimasukan benar dan tombol cancel untuk keluar dari program.

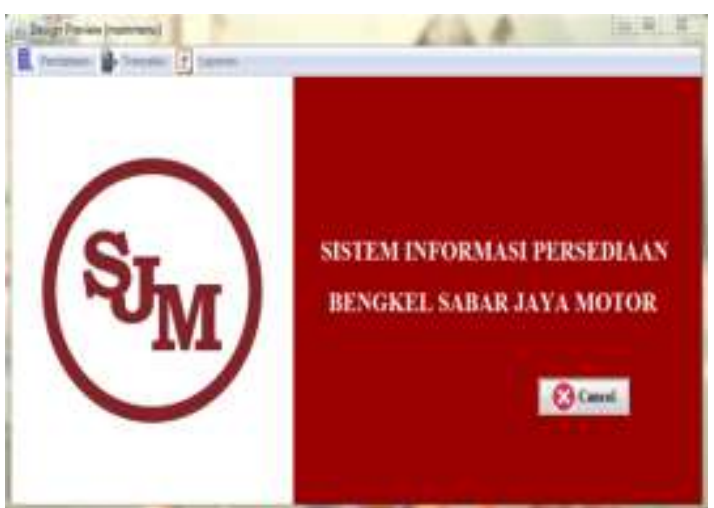

Gambar 10. Tampilan layar main menu

Pada tampilan menu utama terdapat beberapa menu, yaitu menu pendataan, menu transaksi, dan menu laporan serta tombol cancel. 


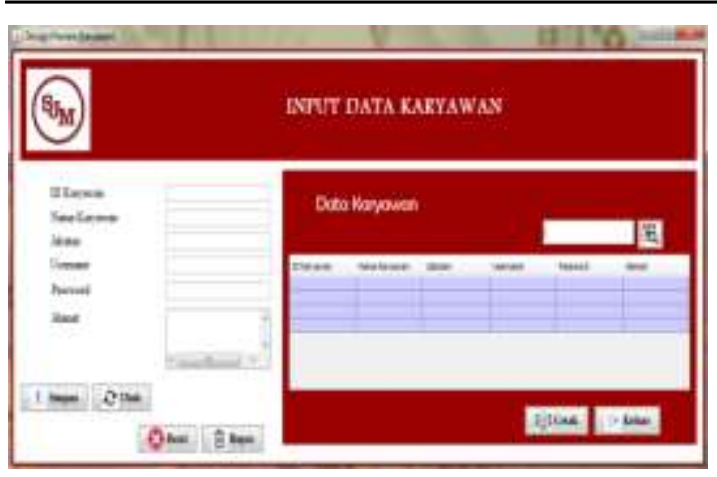

Gambar 11. Tampilan layar karyawan

Pada tampilan format data Karyawan memiliki beberapa tombol yang dapat digunakan untuk menyimpan, mengubah, membatalkan, menghapus, mencetak data karyawan keseluruhan, kembali, dan tombol cari untuk mencari data karyawan yang dinginkan.

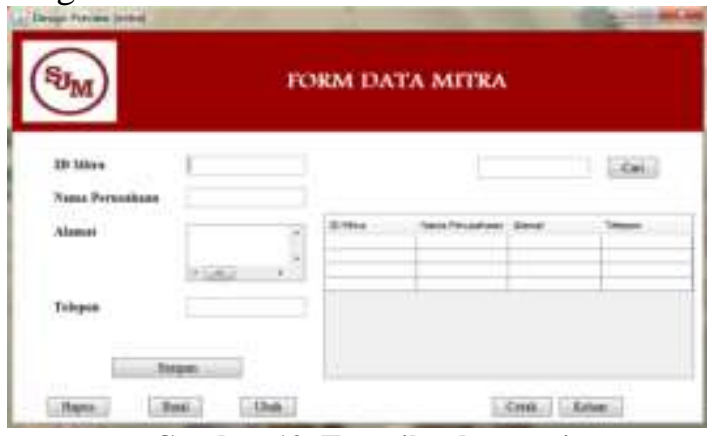

Gambar 12. Tampilan layar mitra

Pada tampilan form data mitra, karyawan dapat menginput data mitra dan memiliki tombol yang dapat digunakan untuk menyimpan, mengubah, membatalkan, menghapus, dan mencetak semua data mitra yang telah di-input. Tombol kembali untuk ke tampilan menu utama.

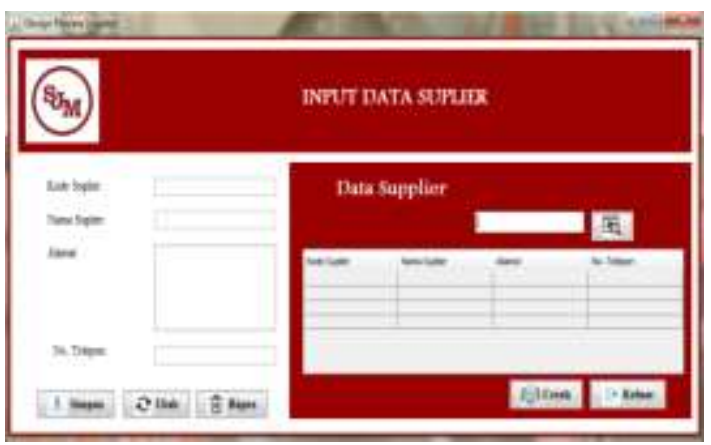

Gambar 13. Tampilan layar supplier

Pada tampilan form data supplier, karyawan dapat menginput data supplier dan memiliki tombol yang dapat digunakan untuk menyimpan, mengubah, membatalkan proses penginputan, menghapus, dan mencetak semua data mitra yang telah di-input.

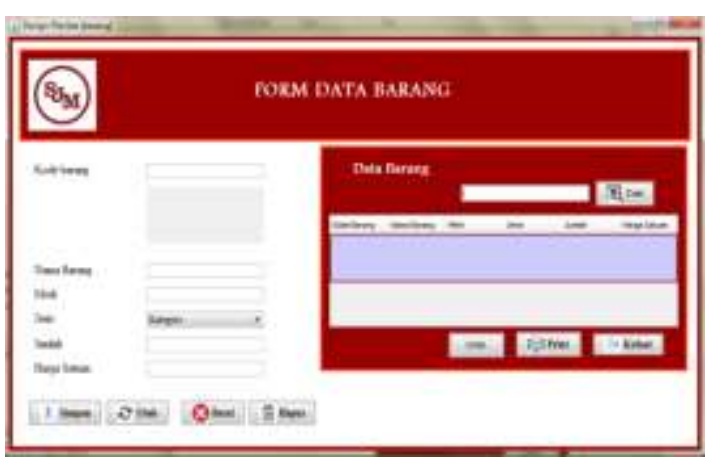

Gambar 14. Tampilan layar barang

Pada tampilan form data barang, karyawan dapat menginput data karyawan dan tampilan ini memiliki tombol yang dapat digunakan untuk menyimpan, mengubah, membatalkan, menghapus, dan mencetak semua data mitra yang telah di-input. Tombol cari untuk mencari data mitra yang dinginkan dan tombol kembali untuk ke tampilan menu utama.

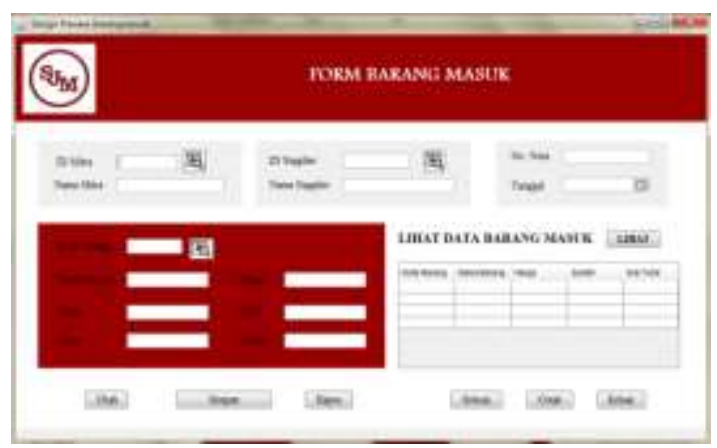

Gambar 15. Tampilan layar barang masuk

Padatampilan form data barang masuk, karyawan dapat melakukan penambahan jumlah data barang masuk, mengubah, dan menghapus data barang masuk. Setelah itu karyawan dapat mencetak transaksi yang telah dilakukan dengan cara menekan tombol cetak.

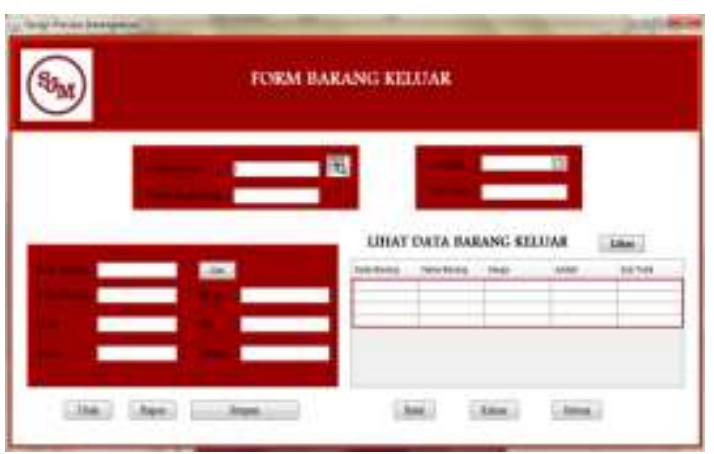

Gambar 16. Tampilan layar barang keluar 
Pada tampilan form data barang keluar, karyawan dapat melakukan penambahan jumlah data barang keluar, mengubah, serta menghapus data barang. Karyawan dapat mencetak transaksi yang telah dilakukan dengan cara menekan tombol cetak.

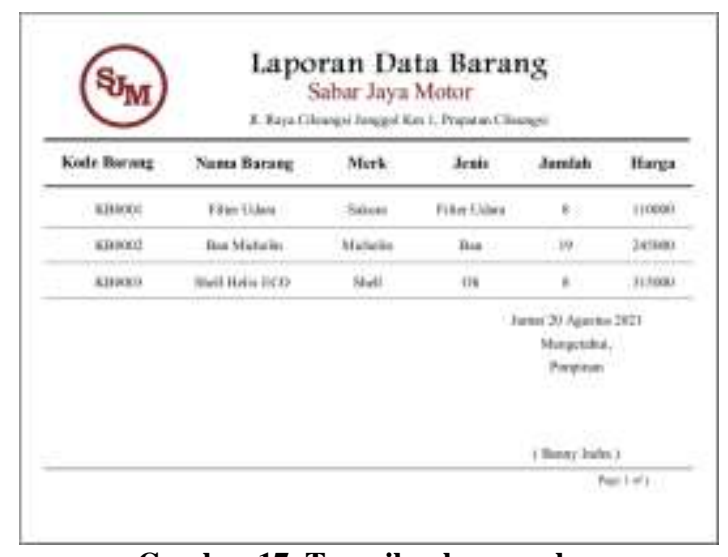

Gambar 17. Tampilan laporan barang

Pada tampilan form laporan data barang ini terdapat detail info tentang data barang seperti kode barang, nama barang, merk barang, jenis barang, jumlah barang dan harga satuan barang. Laporan ini yang kemudian akan dilaporkan kepada owner disetiap bulannya.

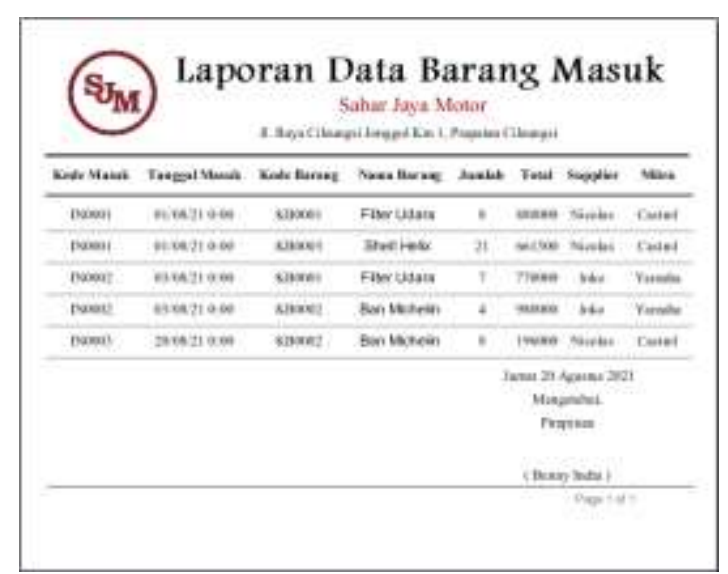

Gambar 18. Tampilan laporan barang masuk

Pada tampilan form laporan data barang masuk adalah tampilan detail dari laporan data barang masuk, yang dimana pada laporan ini terdapat detail info seperti kode masuk, tanggal masuk, kode barang, nama barang, jumlah barang, total, nama supplier dan nama mitra. Laporan ini yang kemudian akan dilaporkan kepada owner perusahaan disetiap bulannya

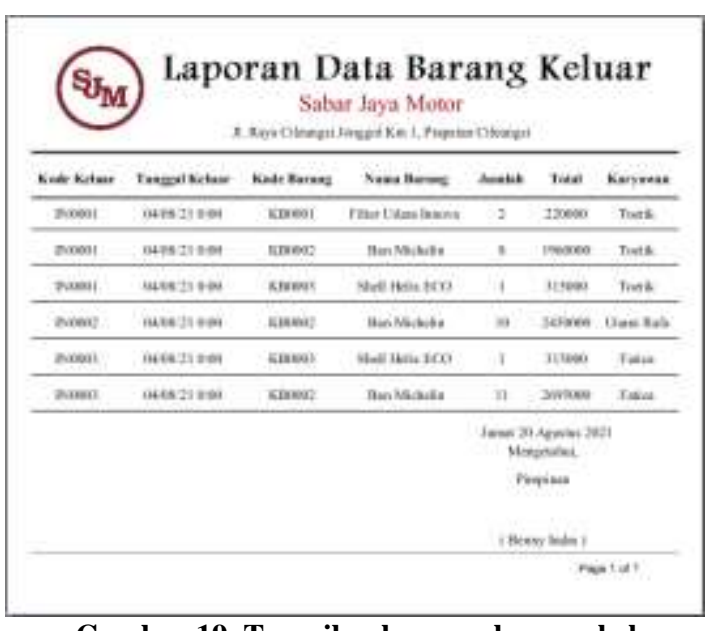

Gambar 19. Tampilan laporan barang keluar

Pada tampilan form laporan data barang keluar adalah tampilan detail dari laporan data barang keluar, yang dimana pada laporan ini terdapat detail info seperti kode keluar, tanggal keluar, kode barang, nama barang, jumlah barang, total, dan nama karyawan. Laporan ini yang kemudian akan dilaporkan kepada owner pada setiap bulannya.

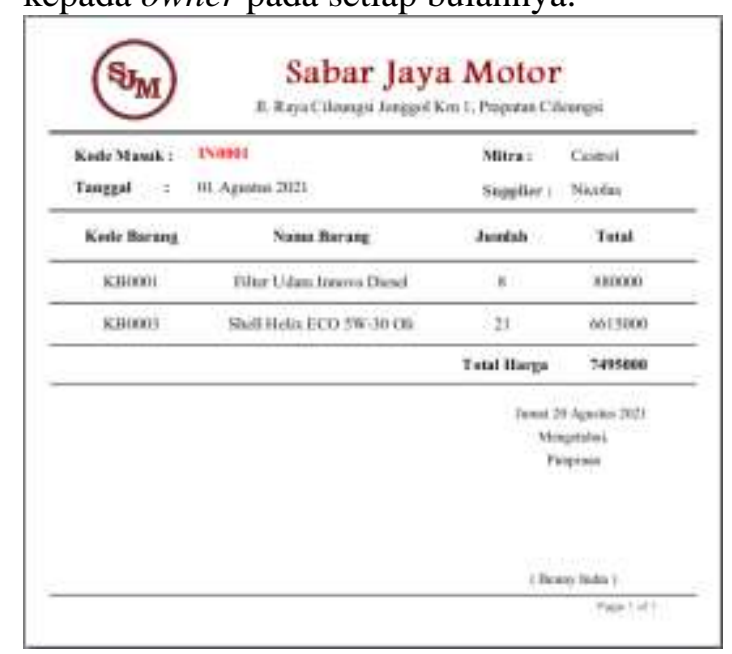

Gambar 20. Tampilan cetak barang masuk

Pada tampilan form Transaksi data barang masuk ini adalah tampilan detail dari Transaksi data barang masuk, yang dimana pada struk barang masuk ini terdapat detail info tentang data barang masuk seperti kode masuk, tanggal masuk, nama supplier, nama mitra, kode barang, nama barang, jumlah, dan total dan total harga keseluruhan. Struk barang masuk ini dikeluarkan setiap ada transaksi barang masuk. 


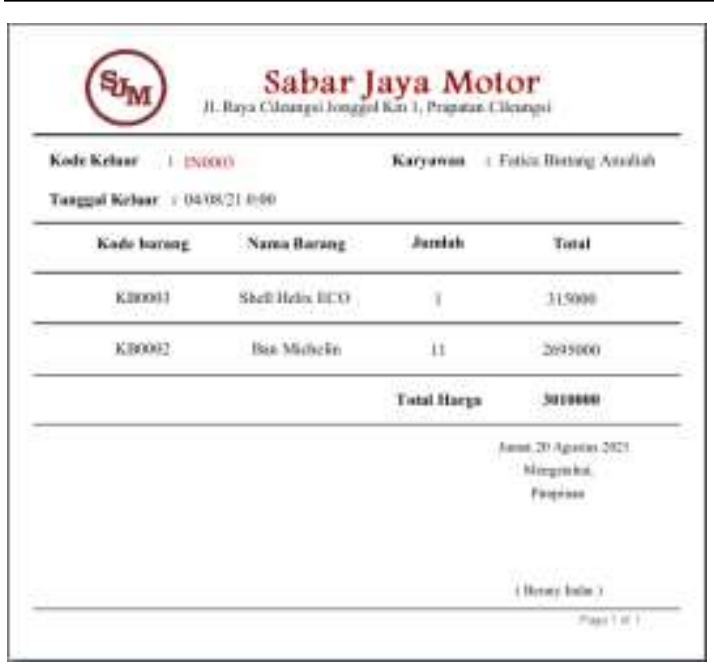

Gambar 21. Tampilan cetak barang keluar

Pada tampilan form Transaksi data barang keluar ini adalah tampilan detail dari Transaksi data barang keluar, yang dimana pada struk barang masuk ini terdapat detail info data barang keluar. Struk barang keluar ini dikeluarkan setiap ada transaksi barang masuk.

\section{SIMPULAN DAN SARAN}

Dengan dibuatnya Sistem Aplikasi Persediaan Barang Pada Bengkel Sabar Jaya Motor. Pada aplikasi ini, Karyawan dapat menangani pekerjaan penginputan data-data barang dengan cepat dan akurat serta dapat di up-date dengan mudah. Dan dengan adanya aplikasi ini diharapkan akan mempermudah kegiatan atau aktivasi pekerjaan karyawan yang membutuhkan kecepatan dan ketepatan data. Kecepatan dan ketepatan dari rencana ini juga membutuhkan kepentingan klien, terutama para pelaksana yang mengelola kerangka kerja yang telah direncanakan. yang memerlukan kecepatan dan ketetapan informasi.

Dengan sistem usulan yang dibuat, maka demi tercapainya suatu tujuan yang diharapkan, maka peneliti dapat memberi saran sebagai berikut: rancangan aplikasi persediaan barang pada Bengkel Sabar Jaya Motor harus didukung oleh sistem yang disiplin dan peraturan yang baik sesuai ketetapan bersama agar dapat berjalan. Data dari informasi yang dimuat dalam aplikasi dapat ditambahkan dengan berbagai informasi lainnya untuk meningkatkan kualitas dalam menjalankan sistem. Peneliti perlu melakukan pengembangan sistem dengan baik agar terciptanya sebuah sistem yang menarik.

\section{DAFTAR PUSTAKA}

Adrifa, R., Kurniawan, R., \& Sofiyan, A. (2018). Perancangan Sistem Pengontrolan Stok Barang Dengan Metode Economic Order Quantity (Eoq). IN F O R M A T I KA, 10(1), 39. https://doi.org/10.36723/juri.v10i1.91

Alleonardo, H. (2014). Jenis-Jenis Barang Dagang. Jurnal Polsri, 6, 7-17.

Ayu, I. G., \& Budiasih, N. (2013). Metode Grounded Theory Dalam Riset Kualitatif. Jurnal Ilmiah Akuntansi Dan Bisnis, 9(1), 19-27.

Fathia Risky, S., \& Evayani. (2016). Analisis dan Perancangan Sistem Informasi Akuntansi Berbasis Data pada Sistem Persediaan dan Penjualan (Studi Kasus pada CV Prima Motor, Banda Aceh). Jurnal Ilmiah Mahasiswa Ekonomi Akuntansi, 1(2), 4558.

Handayani, T., Furqon, A. H., \& Supriyono, S. (2020). Rancang Bangun Sistem Inventori Pengendalian Stok Barang Berbasis Java Pada PT Kalibesar Artah Perkasa. Jurnal SITECH : Sistem Informasi Dan Teknologi, 3(1), 35-40. https://doi.org/10.24176/sitech.v3i1.4884

Huda, N., Widyati, R., Si, S., \& Kom, M. (2021). Rancang Bangun Aplikasi Pendataan Persediaan Barang untuk Proses Stock Opname Menggunakan Barcode Berbasis Android pada Perusahaan Manufaktur. Ilmu Komputer Dan Aplikasi, Vol 1 No 1, 23-32.

Irviani, A. dan. (2019). Anggraeni dan Irviani (2017, 13). Journal of Chemical Information and Modeling, 53(9), 1689-1699.

Susanto, A. (2013). Ii, B A B Pustaka, Tinjauan. $11-44$.

https://elib.unikom.ac.id/files/disk1/700/jbp tunikompp-gdl-boykefitri-34970-7unikom_b-i.pdf

Syafitri, Y., \& Misgianti, E. (2017). Membangun Sistem Informasi Persediaan Barang Dagang ( Studi Kasus : CV Sumber Sejahtera Bandar Lampung ). Jurnal Cendikia, 14(1), 26-32.

Wardhono, V. . W. (2011). Penelitian grounded theory. Bina Ekonomi Majalah Ilmiah Fakultas Ekonomi Unpar, 15(1), 23-35. 